\title{
Ontogeny of osmoregulation in the grapsid crab Armases miersii (Crustacea, Decapoda)
}

\author{
G. Charmantier ${ }^{1, *}$, M. Charmantier-Daures ${ }^{1}$, K. Anger $^{2}$ \\ ${ }^{1}$ Laboratoire d'Ecophysiologie des Invertébrés, Université Montpellier II, Place Eugène Bataillon, \\ F-34095 Montpellier cedex 05, France \\ ${ }^{2}$ Biologische Anstalt Helgoland, Meeresstation, D-27498 Helgoland, Germany
}

\begin{abstract}
Osmoregulation was studied in the zoeal stages I to III, the megalopa, juvenile crab stages $I$ and II, and in adults of the grapsid crab Armases miersii. The larvae hatch and develop in tropical supratidal rock pools, where ample variations of salinity occur. To cope with this harsh environment, the capacity for osmoregulation is well developed at hatching, and becomes further accentuated in the larvae and juveniles. All zoeal stages hyper-regulated at low salinity ( 5 to 26 PSU), but at higher salinity (33 to 44 PSU), they were hyper-osmoconformers. The type of osmoregulation changed in the megalopa stage to a hyper-hypo-regulation pattern. While the hyper-osmoregulatory capacity increased gradually throughout postembryonic development from hatching to adult, the hypo-osmoregulatory capacity increased from the megalopa to the adult. The ontogenic acquisition of osmoregulation was faster for hyper- than for hypo-regulation: 85 and $41 \%$ of the adult capacity, respectively, was acquired in the crab I stage. These findings confirm that important physiological changes occur at metamorphosis. A correlation is established between the osmoregulatory ability of each developmental stage and its salinity tolerance. The ecological implications and the adaptive and evolutionary significance of osmoregulation in early life-history stages of $A$. miersii and other aquatic crustaceans are discussed.
\end{abstract}

KEY WORDS: Osmoregulation Ontogeny - Development - Metamorphosis - Adaptation Crustacea Brachyura $\cdot$ Grapsidae - Larva $\cdot$ Megalopa - Juvenile $\cdot$ Armases

\section{INTRODUCTION}

The importance of physiological adaptations in evolutionary ecology has been underlined in several recent studies, especially with regard to the physiological changes occurring during development, both in vertebrates (e.g. Kormanik 1992, Limburg 1996) and invertebrates (e.g. Charmantier \& Charmantier-Daures 1994, Morritt \& Spicer 1995). Salinity is one of the main environmental factors wielding a selection pressure upon aquatic organisms. Thus, the successful establishment of a species in a given habitat depends on the ability of each of its developmental stages to adapt to, among other factors, the typical level and variations in salinity. This may be achieved through the physiological processes of osmoregulation. In the

•E-mail: charmantier@univ-montp2.fr evolution of the Arthropoda, the ontogeny of osmoregulation has thus a great adaptive significance, and this has stimulated a growing number of studies on different crustacean species

Within the field of evolutionary physiology, the widespread scientific interest in the Crustacea reflects the great variety of habitats that are populated by this group. While osmoregulation has been explored in the adults of numerous crustacean species (reviews in Mantel \& Farmer 1983, Pequeux 1995), the number of species in which the ontogeny of osmoregulation has been studied is still limited (review in Charmantier 1998). This is conspicuous also in the Decapoda and other malacostracans, in which less than 20 species have been studied. The majority of these are edible and have probably, at least partly, been chosen as research objects for their availability and economical interest rather than for their ecophysiological. traits. Additional studies on other crustaceans are thus neces- 
sary to broaden our perspective, and the studied species should be selected chiefly on the basis of their habitat characteristics. In particular, species that live in habitats with extreme and/or highly variable salinities are interesting in this context.

One species fitting this requirement is the semiterrestrial tropical crab Armases miersii (Rathbun, 1897) (formerly Sesarma miersij; for revision of generic taxonomy, see Abele 1992). This grapsid crab breeds in supratidal coastal rock pools on the northern shore of Jamaica, where the larval and early juvenile stages develop under harsh and extremely variable environmental conditions of temperature, oxygen concentration, and salinity (Anger 1995a, Anger \& Schultze 1995, Schuh \& Diesel 1995a). The latter factor shows ample and unpredictible changes in a 0 to 120 PSU range, due to precipitation and evaporation (Anger 1995a, Schuh \& Diesel 1995a). Laboratory experiments showed that the early postembryonic stages, comprising 3 zoeae, 1 megalopa, and the first crab stage, may tolerate a wide range of salinities, from 5 to 50 PSU (Schuh \& Diesel 1995b). The tolerated range tended to broaden in successive slages, which led Anger (1996) to hypothesize that an osmoregulatory capability might already exist in this species from hatching, and that its extent should change during the course of subsequent development.

The objectives of the present study were thus (1) to determine in the successive postembryonic stages, from the zoea I to the second crab stage and in adults, the ability to osmoregulate, and (2) to compare the osmoregulatory capabilities with available data on salinity tolerance and developmental ecology of these life-history stages, highlighting the evolutionary significance of physiological adaptations.

\section{MATERIALS AND METHODS}

Specimens. In 1993, laboratory-reared juveniles from 3 different hatches of Armases miersii were transported from the Discovery Bay Marine Laboratory, Jamaica, to the Marine Biological Station Helgoland, Germany. They were reared to adulthood in 51 aquaria with seawater (ca 32 to 33 PSU salinity), at $24^{\circ} \mathrm{C}$ and a 12:12 h light:dark cycle. Instars I to $V$ were fed exclusively $2 \mathrm{~d}$ old Artemia sp. nauplii, later stages with laboratory-reared marine isopods (Idotea sp.). Larvae have been frequently obtained under these conditions since 1994. The larvae used in the present study hatched from late March through April 1997. They were mass-reared in $400 \mathrm{ml}$ glass bowls at the same conditions of temperature, light and salinity; the initial larval density was 50 individuals per bowl in the zoea I and II stages, 30 in the zoea III, 20 in the megalopa, and
10 in the crab I stage. At daily intervals, seawater was changed and freshly hatched Artemia sp. nauplii were given as food (density: approximately $10 \mathrm{ml}^{-1}$ ). When molts occurred, the larvae were staged individually according to morphological criteria (Zimmermann-Ruf 1997 ) and further reared in groups with an identical age within a given instar

The average duration of successive developmental stages was $3 \mathrm{~d}$ (zoea I), $3 \mathrm{~d}$ (zoea II), $4 \mathrm{~d}$ (zoea III), $8 \mathrm{~d}$ (megalopa), and $8 \mathrm{~d}$ (crab I). Molt stages within each instar (Drach 1939) were routinely determined according to the time elapsed since the last preceding ecdysis, distinguishing between the initial postmolt stages ( $A$ and $B$ ), intermolt (C) in the middle, and premolt (D) near the end of the molting cycle. Except for the study on the effect of the molt stage on osmoregulation (conducted oniy in zoea III), hemolymph samples were collected exclusively from stage $C$ individuals. In zoea I to crab I, this was defined as the nuidule of the time of the instâr.

In later $\mathrm{crab}$ instars, the individual time since the last molt was not known. To select stage $\mathrm{C}$ crabs from these materials, soft (postmolt, $A$ and $B$ ) and strongly colored (premolt, D) individuals wore rejected. The 'crab II' samples had to be taken from a mixed mass culture with about $80 \%$ crab II and $20 \%$ crab I (according to carapace size); 'adult' crabs (males and females with $1.1 \pm 0.3 \mathrm{~cm}$ carapace width) were not fully grown to maximum possible size but sexually mature.

The validity of staging methods was occasionally confirmed through microscopical observations; the telson in larval stages (Anger 1983) and the exopodite of a third maxilliped in crabs (Drach 1939, Drach \& Tchernigovtzeff 1967) were used as reference body parts.

Preparation of media. Experimental media were prepared and stored in 51 plastic containers for the entire duration of the experiments. Dilute media were prepared by adding desalinated freshwater to natural. seawater, and the high salinity medium was prepared by adding 'Tropic Marin ${ }^{\text {( }}$ salts (Wartenberg, Germany) to seawater. All experiments were conducted at a constant temperature of $24^{\circ} \mathrm{C}$. Salinities were expressed as osmotic pressure (in mosm $\mathrm{kg}^{-1}$ ) and as salt content of the medium (in PSU); a value of 3.4 PSU is equivalent to 100 mosm kg $\mathrm{kg}^{-1}\left(29.41\right.$ mosm $\mathrm{kg}^{-1}$ per 1 PSU). The osmotic pressure of the media was measured with a micro-osmometer Model $3 \mathrm{MO}$ (Advanced. Instruments, Needham Heights, MA, USA) requiring 20 il per sample. Media with the following osmolalities (mosm $\mathrm{kg}^{-1}$ ) and corresponding salinities were prepared. 31 (1.1 PSU), 156 (5.3 PSU), 302 (10.3 PSU), 500 (17.0 PSU), 755 (25.7 PSU), 961 (seawater, 32.7 PSU) and 1287 (43.8 PSU). Adult crabs were exposed to al] media; the lowest salinity was not used for younger stages because it was below their range of tolerance (Schuh \& Diesel 1995b, Anger 1996). 
Osmoregulation. Larvae and young crabs (stages I and II) were superficially dried on filter paper, then quickly immersed in mineral oil to avoid evaporation and desiccation. The remaining adherent water was aspirated through a first glass micropipette. The hemolymph was then sampled with a second micropipette inserted in the heart. In adult crabs, the hemolymph was collected via a hypodermic needle after sectioning of the propodite of a fourth or fifth pereiopod previously dried with filter paper. The hemolymph was quickly transferred into mineral oil to avoid evaporation.

Hemolymph osmolality was determined for each life-history stage only after it had reached a steady state value relative to the ambient water osmolality. A preliminary experiment with zoea III larvae and crab I juveniles showed that this occurred within a few hours (see below). Due to the small number of available specimens, a similar evaluation could not be conducted in adult crabs. Based upon results from previous studies with other brachyuran species (Charmantier 1998), adults were kept for ca $48 \mathrm{~h}$ in each experimental medium before sampling. In larvae and early juveniles (crab I and II), we allowed for an acclimation time of 20 to $24 \mathrm{~h}$.

For all developmental stages, hemolymph osmolality was measured with reference to the medium osmolality on a Kalber-Clifton nanolitre osmometer (Clifton Technical Physics, Hartford, NY, USA requiring about $30 \mathrm{nl}$. The results were expressed either as hemolymph osmolality or osmoregulatory capacity (OC), defined as the difference between the osmolalities of hemolymph and the medium. Analysis of variance (ANOVA) and Student's $t$-test were used for multiple and pairwise statistical comparisons of mean values, respectively, after appropriate checks for normal distribution and equality of variance (Sokal \& Rohlf 1995).

\section{RESULTS}

\section{Adaptation time}

The time of adaptation after a change in the environmental salinity was evaluated in the zoea III and crab I stages (Fig. 1). After a rapid transfer from a medium (zoeae: 474 mosm $\mathrm{kg}^{-1}, 16.1 \mathrm{PSU}$; crabs: 499 mosm $\mathrm{kg}^{-1}, 17.0 \mathrm{PSU}$ ) to a more dilute medium (both stages: 156 mosm $\mathrm{kg}^{-1}, 5.3 \mathrm{PSU}$ ), the hemolymph osmolality stabilized in the zoeae within $1 \mathrm{~h}$, and in juvenile crabs within 1 to $2 \mathrm{~h}$.

\section{Effect of the molt stage on osmoregulation}

The effect of the stage of the molting cycle on the osmoregulation of an instar was evaluated in zoea III larvae exposed to 3 salinities (Fig. 2). At the lowest salinity (156 mosm kg-1, 5.3 PSU), the osmoregulatory capacity $(O C)$ was significantly lower in postmolt (stages A and B) than in intermolt and premolt (stages C and D), differing by 14 and $18 \%$, respectively; however, the $O C$ values did not change significantly between stages $\mathrm{C}$ and $\mathrm{D}$. In the 500 mosm $\mathrm{kg}^{-1}$ medium (17 PSU), the OC was only slightly (by $4 \%$ ), but significantly, lower in stages $\mathrm{A}$ and $\mathrm{B}$ than in $\mathrm{C}$; again, the differences between molt stages $C$ and $D$ were statistically not significant. In seawater (961 mosm $\mathrm{kg}^{-1}, 32.7 \mathrm{PSU}$ ), the OC values were generally low, without significant differences among the 3 stages of the molt cycle.

\section{Osmoregulation in successive developmental stages}

The ability of young postembryonic stages and adults to osmoregulate was evaluated over a wide range of tolerable salinities. The results are given as variations in the hemolymph osmolality and as $O C$ in relation to the osmolality and salinity of the medium (Figs. $3 \& 4$ ). In the adults, no difference in osmoregulation was found between males and females; their results were pooled. 


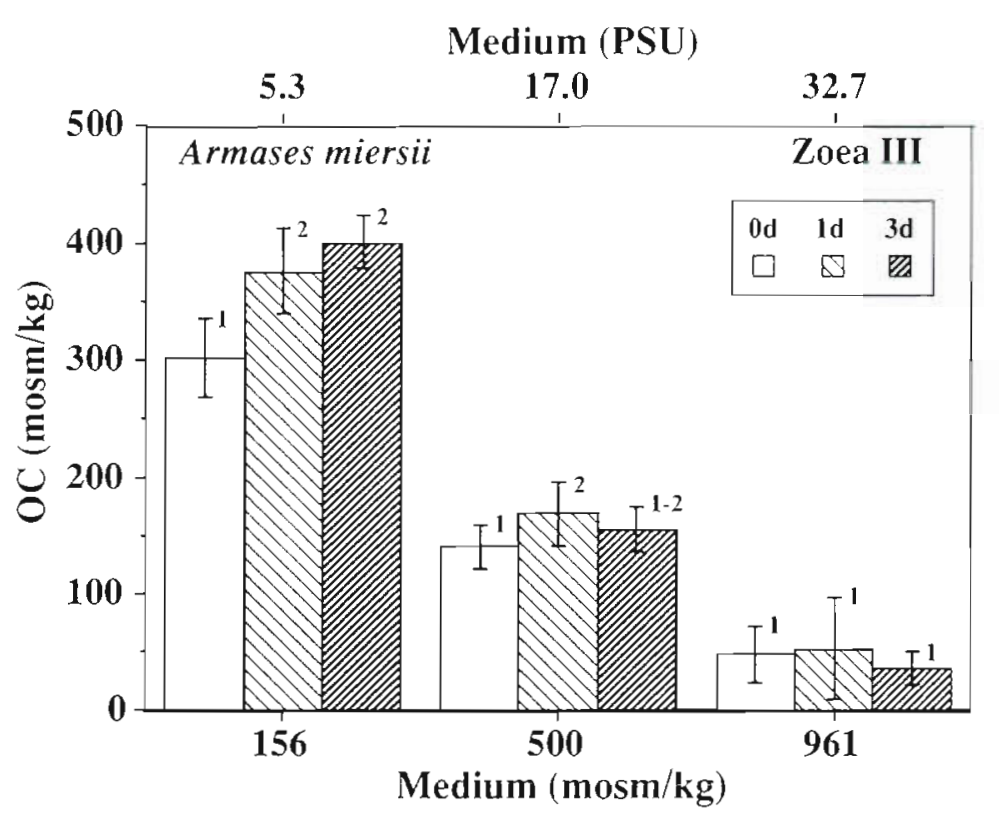

Fig. 2. Armases miersii. Osmoregulatory capacity $(\mathrm{OC})$ in molt stages $A$ and $B$ (early postmolt, $O$ d), C (intermolt, $1 \mathrm{~d}$ ), and D (premolt, $3 \mathrm{~d}$ ) within the zoca III instar during exposure to 3 salinities, at $24^{\circ} \mathrm{C}$; errnr bars: $\bar{x}+$ $\mathrm{SD} ; \mathrm{n}=9$ to 10 individuals; different numbers near error bars indicate significant differences between salinities $(p<0.05)$

The pattern of osmoregulation changed during the course of development. All 3 zoeal stages hyperregulated in the dilute media and isoconformed or slightly hyper-osmo-conformed between 25.7 and 43.8 PSU. A significant shift in the osmoregulatory pattern occurred in the megalopa. This stage retained hyperregulation at low salinities, but also became a slight hypo-regulator in seawater and at enhanced salinity. This type of hyper-hypo-osmoregulation was maintained in the crab I and II juveniles and in the adults (Fig 3). In particular, adult crabs were very strong hyper-regulators at low salinity (down to 1.1 PSU) and strong hypo-regulators in seawater and higher salinity. In the 4 experimental media ranging from 302 to 961 mosm $\mathrm{kg}^{-1}$ (10.3 to 32.7 PSU), adult Armases miersii maintained an almost constant hemolymph osmolality (mean values: $733,749,770,810$ mosm kg-1).

The ability to osmoregulate at both low and high salinities increased throughout development, as demonstrated by variations in hemolymph osmolality (Fig. 3) or OC (Fig. 4). At low salinities (5.3 to $17.0 \mathrm{PSU}$, the hyper-osmoregulatory capacity increased in general progres- sively from the zoea I to the adults. As exceptions, the $\mathrm{OC}$ in dilute media remained unchanged between the roea III and the megalopa stages, and, at some salinities, the ontogenic changes in $O C$ were not significant between the zoea II and III or between the crab I and II stages (Fig. 4). At high salinities (32.7 and 43.8 PSU), the weakly hyper-osmoconforming trait remained unchanged between the zoeal stages I and III, while the hypo-osmoregulatory capacity increased from the megalopa to the adult crab. In megalopae, juveniles and adult crabs, the transition from hyper- to hyporegulation, i.e. the isosmotic salinity, was close to 26-27 PSU (Fig. 3).

\section{DISCUSSION}

\section{Adaptation time}

In Armases miersii, the time required for osmotic equilibration after a sudden decrease in external salinity was about 1 to $2 \mathrm{~h}$ in the 2 tested stages, zoea III and crab I. This time is similar to those found in young stages of other decapod or isopod species (review in Charmantier 1998). For instance, in the closely related grap-

\section{Medium (PSU)}

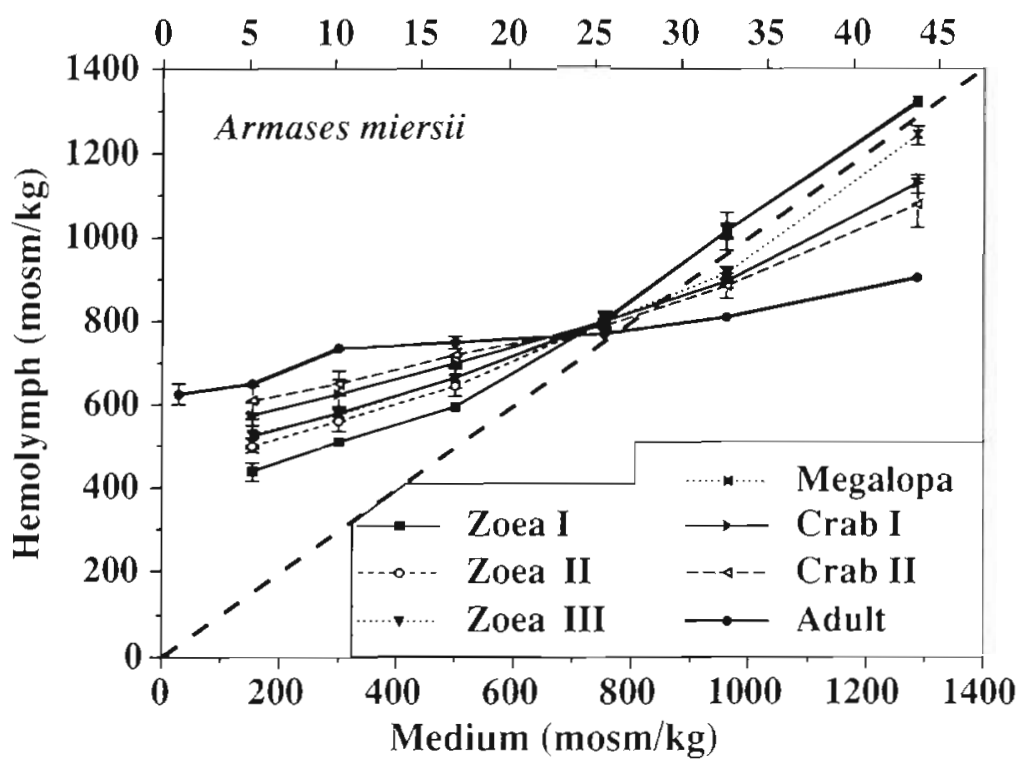

Fig. 3. Armases miersii. Variations of the hemolymph osmolality in different stages of postembryonic development in relation to the osmolality and salinity of the medium at $24^{\circ} \mathrm{C}_{i}$ error bars: $\bar{x} \pm \mathrm{SD} ; \mathrm{n}=8$ to 11 individuals; dashed line: isoconcentration 
sid crab species Sesarma reticulatum, the adjustment time of the zoeal stages I and II was also about $1 \mathrm{~h}$ (Foskett 1977). The brevity of adaptation time indicates a fast exchange of water and ions between the organism and the external medium, most likely linked to small body size (i.e. large surface/volume ratio) and high permeability of the body surface. In $A$. miersii, the early life-history stages are subject to frequent and ample variations in salinity in their particular habitat, resulting in changes in their hemolymph osmolality. Even attenuated through the high osmoregulatory abilities in this species, these changes must certainly be compensated for by cell volume regulation, i.e. isosmotic intracellular regulation.

\section{Effects of the molt stage}

Significant effects of the molting cycle on osmoregulation were noted in the zoea III only at low salinity. The $O C$ and thus also hemolymph osmolality were conspicuously lower immediately after ecdysis (i.e. during postmolt, stages $\mathrm{A}$ and $\mathrm{B}$ ) than during the later stages, intermolt (C) and premolt (D). This effect following ecdysis might result from a passive diffusional and osmotic uptake of water through the highly permeable postmolt teguments, favoured by the large difference in osmolality between the external medium and the hemolymph.

In contrast to other species (review in Charmantier 1998), no significant increase in hemolymph osmolality was noted in premolt. This effect has been interpreted as an adaptation ensuring the entry of water into the body for an increase in volume at the time of ecdysis (Kalber \& Costlow 1966). In Armases miersii, the increase in larval body size at ecdysis would thus result, at least at low salinity, from its strong osmoregulatory ability, which ensures a high hemolymph osmolality. On a more general level, the variability in hemolymph osmolality during the molting cycle, even if it is limited as in A. miersii larvae, highlights again the necessity for checking the molt stage in comparative studies of osmoregulation.

\section{Osmoregulation in successive developmental stages}

Adult Armases miersii hyper-regulate at low salinities and hypo-regulate in undiluted seawater and at higher salt concentrations. The isosmotic salinity is
Medium (PSU)

\section{$\begin{array}{lllllll}1.1 & 5.3 & 10.3 & 17.0 & 25.7 & 32.7 & 43.8\end{array}$}

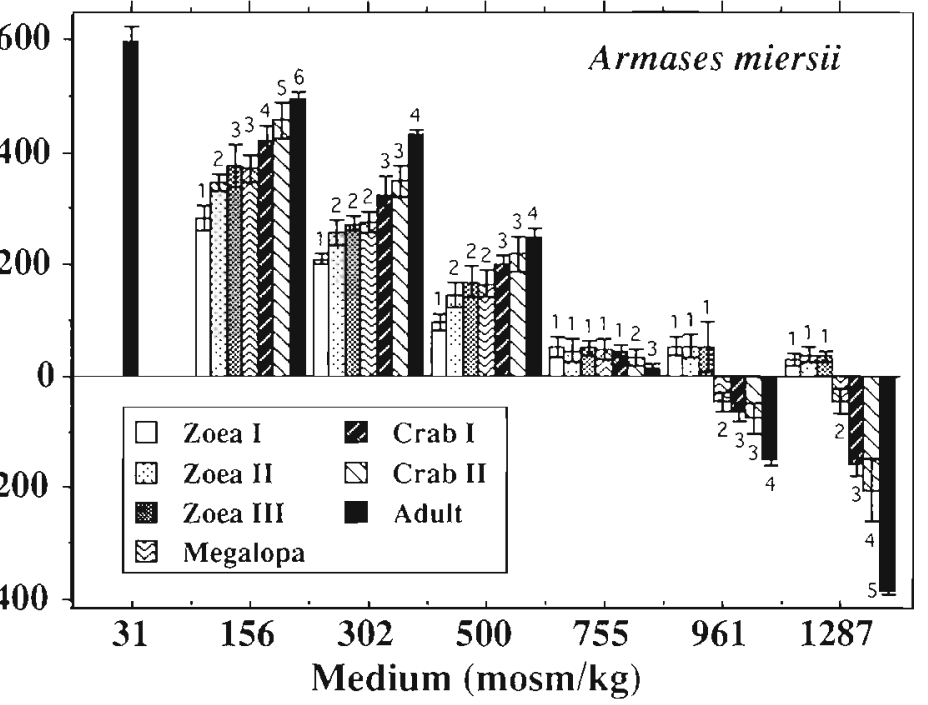

Fig. 4. Armases miersii. Variations of the osmoregulatory capacity (OC) in different stages of postembryonic development in relation to the osmolality and salinity of the medium at $24^{\circ} \mathrm{C}$; error bars: $\bar{x} \pm \mathrm{SD} ; \mathrm{n}=8$ to 11 individubetween salinities $(p<0.05)$

close to 26-27 PSU. Although the ability to osmoregulate varies among species and with other factors such as temperature and body size, this pattern is common among species belonging to different families of the Brachyura (Mantel \& Farmer 1983). At low salinities, the hyper-osmoregulatory capacity of A. miersii reached up to 600 mosm $\mathrm{kg}^{-1}$. This value is close to those reported from other Grapsidae, particularly in Sesarminae such as Sesarma meinerti (Gross et al. 1966), S. catenata, S. eulimene (Boltt \& Heeg 1975), and $S$. reticulatum (Foskett 1977), but also in species belonging to the family Ocypodidae (review in Mantel \& Farmer 1983), e.g. Uca subcylindrica (Rabalais \& Cameron 1985a).

At high salinity, the hypo-osmoregulatory capacity of adult Armases miersii is strong, e.g. about -400 mosm $\mathrm{kg}^{-1}$ in a 44 PSU medium. At approximately the same salinity, a similar value was measured in Sesarma meinerti (Gross et al. 1966) and in some UCa species (review in Mantel \& Farmer 1983); on the other hand, the hypo-osmoregulatory capacity of $S$. reticulatum is only about -200 mosm $\mathrm{kg}^{-1}$ (Foskett 1977).

Adult Armases miersii are among the most efficient osmoregulators amid the decapod crustaceans. This may be illustrated in 2 additional ways: (1) this species maintains an almost constant hemolymph osmolality at salinities between 10 and $33 \mathrm{PSU}_{\text {; }}$ (2) over the entire range of tested salinities (1 to $44 \mathrm{PSU}$, i.e. for external 
osmolalities spanning 1250 mosm $\mathrm{kg}^{-1}$ ), the variation in hemolymph osmolality remained below 300 mosm $\mathrm{kg}^{-1}$.

The patterns of osmoregulation change during the postembryonic development in Armases miersii. Zoeae are hyper-isoregulators, with an increasing ability to hyper-regulate at low salinity, especially from the zoea I to the zoea II stage. The adult hyper-hypo-osmoregulatory type is established in the megalopa: at this stage however, the ability to hyper-regulate is not higher than in the zoea III, and the ability to hypo-regulate is still very limited. In the subsequent juvenile crab I and II stages, both the hyper- and hypo-osmoregulatory capacities increase, and they certainly continue to increase in later juvenile stages, until the adult capacity is eventually reached. The ability to osmoregulate is established in 2 steps during the postembryonic development of A. miersii: (1) the larvae are from hatching able to hyper-isoregulate; (2) the capability for hyperhypo-regulation is acquired at the megalopa stage.

This ontogenic change in the patterns of osmoregulation can be compared with that in other species, and it may be assigned to one of 3 different types that have been proposed (Charmantier et al. 1988; review in Charmantier 1998). Armases miersii belongs to the third category, in which the pattern of osmoregulation changes during the postembryonic development. In another grapsid species, Sesarma reticulatum, the zoeal stages are also hyper-isoregulators and the adult crabs hyper-hypo-regulate, as in $A$. miersii, but the megalopa stage retains the zoeal pattern of osmoregulation; thus, the transition from the larval to the adult pattern of osmoregulation should in that species occur only during the early juvenile crab stages (Foskett 1977). The ontogenic changes found by Rabalais \& Cameron (1985b) in the ocypodid crab Uca subcylindrica resemble more closely those in $A$. miersii: its 2 zoeal stages are hyper-isoregulators, and the shift to the adult hyper-hypo-regulation pattern occurs already in the megalopa stage. In all these crab species, the change in the pattern of osmoregulation is obviously linked with metamorphosis, as in other previously studied species.

In general, the transition from the larval to the adult type of osmoregulation may occur abruptly in 1 metamorphic molt, as in lobsters Homarus americanus, or it may represent a more gradual change. The latter occurs in species where metamorphosis is spread over several molts, e.g. in Penaeus japonicus and probably other penaeid shrimps (Charmantier et al. 1988). In the literature, there are controversial views of the timing of metamorphosis in brachyurans. It may refer to the molt from the megalopa to first crab stage (Costlow 1968), to that from the last zoea to the megalopa (Felder et al. 1985), or to both molts (see discussion in Gore 1985 ,
Charmantier \& Charmantier-Daures 1991). In Cancer irroratus (Charmantier \& Charmantier-Daures 1991), probably also in Sesarma reticulatum (Foskett 1977), the change in the osmoregulatory pattern occurs after the molt between the megalopa and the first crab stage. In Armases miersii and in Uca subcylindrica, in contrast, this change is accomplished earlier, at the zoea-megalopa transition. These findings support the interpretation that metamorphosis in the brachyuran is spread over 2 molts. Moreover, our observations stress the need to consider physiological changes as a part of metamorphosis, since transitions from the larval to the adult pattern (if these are different) should primarily occur during this developmental event.

During ontogeny, a strong correlation has often been observed between an increasing ability to osmoregulate and an improving salinity tolerance. This has been documented in several crustacean species such as the isopod Sphaeroma serratum (Charmantier \& Charmantier-Daures 1994) and, among the decapods, in Macrobrachium petersi (Read 1984), Uca subcylindrica (Rabalais \& Cameron 1985b), Homarus americanus, Penaeus japonicus (Charmantier et al. 1988), and Cancer irroratus (Charmantier \& Charmantier-Daures 1991). A similar relationship may be established in Armases miersii. In rearing experiments at $25^{\circ} \mathrm{C}$, complete development from hatching to the first crab stage has been observed in a wide range of salinities, from 5 to 50 PSU (Schuh \& Diesel 1995b), and salinity tolerance changed in successive stages (Anger 1996). Anger (1996) noted that the tolerance of low salinity tended to increase during development from the zoea I to the crab stage I. After the present study, we may relate this trend to the concomitant increase in the larval ability to hyper-regulate; at 5 PSU salinity, $85 \%$ of the hyper-osmoregulatory capacity of the adults is already acquired in the crab I stage.

The relation between the ontogeny of osmoregulation and tolerance of high salinities, however, is not as clear. The mortality rates of successive stages remained high under hypersaline conditions (Anger 1996), despite the appearance of a hypo-regulation ability in the megalopa. This may partly be explained by our observation that the hypo-osmoregulatory capacity in the crab I stage represents, at 44 PSU salinity, only $41 \%$ of the adult capacity. We thus suppose that the survival at enhanced salinities may increase in later juvenile crab stages, when the mechanisms of hypo-regulation are more efficient.

In Armases miersii, the ontogenic acquisition of osmoregulatory abilities is faster for hyper- than for hypo-regulation. The origin of this physiological heterochrony, reported for the first time in crustaceans, remains hypothetical (see below). As the ability to osmoregulate originates from specialized tissues and 
organs (review in Charmantier 1998), their structural and functional ontogeny will be an interesting field for future research throughout the development of $A$. miersii.

The relationships between osmoregulation and salinity tolerance have important ecological implications and evolutionary significance. The possession of high osmoregulatory capabilities at hatching, which increase in later developmental stages, is one of the adaptive factors permitting the development of Armases miersii in supratidal rock pools. In this physically harsh habitat, extreme conditions of salinity are common, with sudden drops following rainfalls and, less frequently, periods of slow evaporative increase in salinity (Anger 1995a, Anger \& Schultze 1995, Schuh \& Diesel 1995a). Different levels of selection pressure exerted by low and high salinities, respectively, might thus account for the evolutionary acquisition of a fastincreasing ability to hyper-regulate and a slow-growing ability to hypo-regulate.

Beside a high level of osmoregulation, further adaptations to the conditions in rock pools have been detected in the postembryonic stages of Armases miersii, including metabolic, nutritional and reproductive traits (Schuh \& Diesel 1995b, review in Anger 1995b). Similar ecophysiological correlations have been established for the early life-history stages of Uca subcylindrica, which also encounter extreme salinity variations in their nursery habitats, temporary rainfall puddles (Rabalais \& Cameron 1985b). Likewise, this relationship was shown for the developmental stages of the isopod Sphaeroma serratum in shallow coastal waters of lagoons (Charmantier \& Charmantier-Daures 1994). Among the few species studied as yet, an ontogenic increase in both osmoregulation and salinity tolerance thus appears to be common. This correlation should be important, as it permits ontogenic migrations between habitats with different salinity regimes, as e.g. in Macrobrachium petersi (Read 1984) and Penaeus japonicus (Charmantier et al. 1988). In the latter case, osmoconforming stenohaline larvae hatch and develop in the open sea, and only the osmoregulating euryhaline postlarvae can enter coastal lagoons.

The establishment of a species in a habitat with ample salinity variations requires strong osmoregulatory abilities. From the available studies it appears that crustaceans have evolved 2 alternative adaptive strategies to achieve this goal. In one of them, the larvae are conformers, and colonization of a physically harsh environment is accomplished through re-immigration of late developmental stages, following the onset of an efficient osmoregulation (usually at metamorphosis). The second strategy, in which a great ability to osmoregulate is already present at hatching, is exemplified by Armases miersii. Although this capability is initially limited and, thus, increases through development, it permits the entire postembryonic development in a land-locked habitat such as supratidal rock pools. This strategy is probably based on an early development of osmoregulatory tissues and organs during embryogenesis and a rapid maturation after hatching, particularly at metamorphosis. Since these traits allow for an enhanced emancipation from the original habitat, the sea, they may represent an important prerequisite for the evolutionary conquest of non-marine environments. Thus, the ontogeny of the structure and functionality of osmoregulatory systems should be further investigated in species like $A$. miersii.

Acknowledgements. We thank Prof. Dr F. Buchholz, Director, Biologische Anstalt Helgoland, Meeresstation, for receiving G.C. and M.C.-D. at Helgoland; K. Riesebeck, K. Paschke, K. Pfaff, and $G$. and $L$. Gimenez, for occasional technical help: and $M$. A. Garcia for secretarial assistance. A grant from the French Ministère des Affaires Etrangères was awarded to G.C.

\section{LITERATURE CITED}

Abele LG (1992) A review of the grapsid crab genus Sesarma (Crustacea: Decapoda: Grapsidae) in America, with the description of a new genus. Smithsonian Contr Zool 527 : $1-60$

Anger K (1983) Moult cycle and morphogenesis in Hyas araneus larvae (Decapoda, Majidae), reared in the laboratory. Helgoländer Meeresunters 36:285-302

Anger K (1995a) Developmental biology of Armases miersii (Grapsidae), a crab breeding in supratidal rock pools. II. Food limitation in the nursery habitat and larval cannibalism. Mar Ecol Prog Ser 117:83-89

Anger K (1995b) The conquest of freshwater and land by marine crabs: adaptations in life-history patterns and larval bioenergetics. J Exp Mar Biol Ecol 193:119-145

Anger K (1996) Salinity tolerance of the larvae and first juveniles of a semiterrestrial grapsid crab, Armases miersii (Rathbun). J Exp Mar Biol Ecol 202:205-223

Anger K, Schultze K (1995) Elemental composition (CHN), growth and exuvial loss in the larval stages of two semiterrestrial crabs, Sesarma curacaoense and Armases miersii (Decapoda: Grapsidae). Comp Biochem Physiol 111A: $615-623$

Boltt G, Heeg J (1975) The osmoregulatory ability of three grapsoid crab species in relation to their penetration of an estuarine system. Zool Afr 10:167-182

Charmantier G (1998) Ontogeny of osmoregulation in Crustaceans: a review. Inv Repr Dev (in press)

Charmantier G, Charmantier-Daures M (1991) Ontogeny of osmoregulation and salinity tolerance in Cancer irroratus; elements of comparison with $C$. borealis (Crustacea, Decapoda). Biol Bull (Woods Hole) 180:125-134

Charmantier G, Charmantier-Daures M (1994) Ontogeny of osmoregulation and salinity tolerance in the isopod crustacean Sphaeroma serratum. Mar Ecol Prog Ser 114:93-102

Charmantier G, Charmantier-Daures M, Bouaricha N, Thuet P. Aiken DE, Trilles JP (1988) Ontogeny of osmoregulation and salinity tolerance in two decapod crustaceans Homarus americanus and Penaeus japonicus. Biol Bull (Woods Hole) 175:102-110 
Costlow JD (1968) Metamorphosis in crustaceans. In: Etkin W, Gilbert LI (eds) Metamorphosis: a problem in developmental biology. Appleton-Century-Crofts, New York, p $3-41$

Drach P (1939) Mue et cycle d'intermue chez les crustacés décapodes. Annls Inst Océanogr Monaco 19:103-391

Drach P, Tchernigovtzeff C (1967) Sur la méthode de détermination des stades d'intermue et son application générale aux crustacés. Vie Milieu 18A:595-609

Felder DL, Martin JW, Goy JW (1985) Patterns in early postlarval development of decapods. In: Wenner AM (ed) Larval growth, crustacean issues, Vol 2. AA Balkema, Rotterdam, p 163-225

Foskett JK (1977) Osmoregulation in the larvae and adults of the grapsid crab Sesarma reticulatum Say. Biol Bull Mar Biol Lab Woods Hole 153:505-526

Gore RH (1985) Molting and growth in decapod larvae. In: Wenner AM (ed) Larval growth, crustacean issues, Vol 2 AA Balkema, Rotterdam, p 1-65

Gross WJ, Lasiewski RD, Dennis J, Rudy P (1966) Salt and water balance in selected crabs of Madagascar. Comp Biochem Physiol 17:641-660

Kalber FA, Costlow JD (1966) The ontogeny of osmoregulation and its neurosecretory control in the decapod crustacean Rhithropanopeus harrisij. Am Zool 6:221-229

Kormanik GA (1992) Ion and osmoregulation in prenatal elasmobranchs: evolutionary implications. Am Zool 32 . 294-302

Limburg KE (1996) Modelling the ecological constraints on growth and movement of juvenile American shad (Alosa sapidissima) in the Hudson River estuary. Estuaries 19: $794-813$

Mantel LH, Farmer LL (1983) Osmotic and ionic regulation. In: Mantel LH (ed) The biology of Crustacea, Vol 5, inter-

Editorial responsibility: Otto Kinne (Editor),

Oldendorf/Luhe, Germany nal anatomy and physiological regulation. Academic Press, New York, p 53-161

Morritt D, Spicer JI (1995) Changes in the pattern of osmoregulation in the brackish water amphipod Gammarus duebeni Lilljeborg (Crustacea) during embryonic development. J Exp Zool 273:271-281

Pequeux A (1995) Osmotic regulation in crustaceans. J Crustac Biol 15:1-60

Rabalais NN, Cameron JN (1985a) Physiological and morphological adaptations of adult Uca subcylindrica to semi-arid environments. Biol Bull (Woods Hole) 168:135-146

Rabalais NN, Cameron JN (1985b) The effects of factors important in semi-arid environments on the early development of Uca subcylindrica. Biol Bull (Woods Hole) 168: $147-160$

Read GHL (1984) Intraspecific variation in the osmoregulatory capacity of larval, post-larval, juvenile and adult Macrobrachium petersi (Hilgendorf). Comp Biochem Physiol 78A:501-506

Schuh M, Diesel R (1995a) Breeding in a rockpool: larvae of the semiterrestrial crab Armases (=Sesarma) miersii (Rathbun) (Decapoda: Grapsidae) develop in a highly variable environment. J Exp Mar Biol Ecol 18.5:10y-129

Schuh M, Diesel R (1995b) Effects of salinity, temperature, and starvation on the larval development of Armases (= Sesarma) miersii (Rathbun, 1897), a semiterrestrial crab with abbreviated development (Decapoda: Grapsidae). $J$ Crustac Biol 15:205-213

Sokal RR, Rohlf FJ (1995) Biometry. The principles and practice of statistics in biological research. WH Freeman and Co, San Francisco

Zimmermann-Ruf C (1997) Larvalentwicklung von Armases miersii (Rathbun, 1897). Eine morphologische Betrachtung. Thesis, University of Heidelberg, p 1-70

Submitted: November 21, 1997; Accepted: January 26, 1998 Proofs received from author(s): March 2, 1998 